\title{
Guideline-based survey of outpatient COPD management by pulmonary specialists in Germany
}

This article was published in the following Dove Press journal:

International Journal of COPD

13 February 2012

Number of times this article has been viewed

\author{
Thomas Glaab ${ }^{1,2}$ \\ Claus Vogelmeier ${ }^{3}$ \\ Andreas Hellmann ${ }^{4}$ \\ Roland Buhl' \\ 'Department of Respiratory \\ Diseases III, Medical Center of the \\ Johannes Gutenberg-University, Mainz, \\ 2Medical Affairs Germany, Respiratory \\ Medicine, Boehringer Ingelheim \\ Pharma GmbH and Co, KG, Ingelheim, \\ ${ }^{3}$ Department of Respiratory Diseases, \\ University Hospitals of Giessen \\ and Marburg, Marburg, ${ }^{4}$ Federal \\ Association of Pneumologists, \\ Augsburg, Germany
}

Correspondence: Thomas Glaab Boehringer Ingelheim Pharma GmbH and Co, KG, Medical Affairs Germany, Respiratory Medicine, Binger Str 173, D-552 16 Ingelheim am Rhein, Germany $\mathrm{Tel} / \mathrm{Fax}+496132723344$ Email thomas.glaab@boehringeringelheim.com
Background: Little is known about the role of guidelines for the practical management of chronic obstructive pulmonary disease (COPD) by office-based pulmonary specialists. The aim of this study was to assess their outpatient management in relation to current guideline recommendations for COPD.

Methods: A nationwide prospective cross-sectional COPD questionnaire survey in the form of a multiple-choice questionnaire was sent to 1000 office-based respiratory specialists in Germany. The product-neutral questions focused on routine COPD management and were based on current national and international COPD guideline recommendations being consistent in severity classification and treatment recommendations.

Results: A total of 590 pulmonary specialists (59\%) participated in the survey. Body plethysmography was considered the standard for diagnosis $(65.9 \%)$, followed by spirometry $(32 \%)$. Most respondents were able to cite the correct spirometric criteria for classifying moderate $(87 \%)$ to very severe COPD $(77 \%)$. A quarter of the respondents equated the World Health Organization (WHO) definition of chronic bronchitis with COPD. Notably, most participants preferred the updated national COPD guidelines (51.4\%) to the Global Initiative for Chronic Obstructive Lung Disease (GOLD) guidelines (40.2\%). Improvement of functional exercise capacity and quality of life were considered the two most relevant treatment goals; whereas impact on mortality was secondary. Treatment of COPD largely complied with the guidelines. However, a significant percentage of the pulmonary specialists differed in their assessment of the benefits of various therapeutic measures from evidence-based results. Referral for pulmonary rehabilitation was uncommon, regardless of the severity of COPD.

Conclusion: The findings of this large national survey suggest that most pulmonary specialists adhere to the current COPD guideline recommendations in daily practice. However, physicians' knowledge of guidelines is not sufficient as the sole benchmark when assessing their implementation in day-to-day practice. Necessary changes in the health care system must include more effective ways to transfer knowledge to clinical practice and to give access to interventions of proven clinical benefit.

Keywords: pulmonary rehabilitation, survey, GOLD, clinical outcomes, therapy, diagnosis

\section{Introduction}

Chronic obstructive pulmonary disease (COPD) is one of the most significant chronic conditions worldwide and is now the fourth most common cause of death, resulting in an enormous, steadily increasing economic and social burden. ${ }^{1-3}$ COPD is regarded as a preventable and treatable disease. Consequently, greater focus on early diagnosis and appropriate treatment may prevent and improve symptoms, 
reduce the rate and severity of exacerbations, improve quality of life, improve exercise capacity and physical activity, and prolong survival. ${ }^{4}$ In recent years, evidencebased clinical guidelines have been developed at both the national and international level in an effort to help doctors diagnose, treat, and prevent this condition. ${ }^{5-7}$ The diagnostic and therapeutic recommendations of the current German COPD guidelines are based on the international Global Initiative for Chronic Obstructive Lung Disease (GOLD) guidelines. ${ }^{7}$

A number of studies suggest that there are substantial gaps between recommended and real life management of COPD patients in primary care practice. ${ }^{8-13}$ The extent to which guidelines are accepted and implemented differs widely from one group of doctors to another. ${ }^{14}$ We hypothesized that pulmonary specialists, who generally have a better knowledge of lung diseases, are more likely to adhere to COPD guidelines. ${ }^{15}$ In general, little is known about the current practice patterns of respiratory specialists in outpatient care. A recent survey studied the guideline conformity of COPD management among pulmonary specialists and general practitioners, revealing deficiencies with regard to the diagnosis, treatment, and implementation of educational measures in COPD. ${ }^{16}$ However, this study was based on the outdated German COPD guidelines from $2002^{17}$ which differed from the current German and GOLD guidelines in essential points, such as the classification of COPD severity and treatment. The aim of this nationwide survey with 1000 office-based pulmonary specialists in Germany was to investigate their COPD management and how this compares with current national and international guideline recommendations.

\section{Methods}

Anonymized questionnaires were sent with a stamped addressed envelope to 1000 office-based pulmonary specialists (or pulmonary group practices) in Germany. Physicians were selected from a representative national physicians' register. There was a total of 1088 officebased pulmonary specialists at the time of the investigation (OneKey database, Cegedim, Bensheim, Germany). Academic institutions or hospitals were not included in the survey.

The self-administered postal questionnaire survey was based on current national COPD guidelines. ${ }^{5,7}$ It had 43 multiple choice questions, focusing on the following items:

- Epidemiology and diagnosis of COPD

- Patient education
- Treatment

- Knowledge and acceptance of current COPD guidelines

- Questions regarding the physician's practice.

The questionnaire had been applied in a similar format in a previous survey. ${ }^{16}$ Non-responders were not followed up and no reminders were sent during the 4-month term of the survey. Physicians were paid 75 euro as compensation for participation in the survey.

\section{Statistics}

DCAS (DCAS Software Solutions Inc, Plano, TX) software (Medidata GmbH, Konstanz, Germany) and SAS software (v 9.1.3; SAS Institute Inc, Cary, NC) were used for statistical analysis of the anonymous, machine-readable questionnaires. The frequencies for each category, in relation to the total number of responses, are given in text results and Tables 1-3. The anonymized data were analyzed by Medidata.

\section{Results Demographics}

Fifty-nine percent of the 1000 questionnaires sent out were returned ( $n=590$ physicians). Ninety-six percent of the physicians were pulmonary specialists. The data quality was very good, as reflected by the low frequency of missing data $(\leq 3.1 \%)$. The demographic data of the participants are shown in Table 1. Forty-eight percent of pulmonary specialists reported that they treat 101-200 COPD patients per month. Thirty-six percent of the physicians reported treating $>200$ COPD patients per month, primarily patients with moderate COPD. Fifty-four percent of the respondents reported that $5 \%-15 \%$ of their patients showed an overlap of asthma and COPD.

\section{Epidemiology and risk factors}

The incidence of COPD is increasing according to $90 \%$ of the physicians and $94 \%$ of the physicians regard COPD as a big or very big "public health" problem in Germany. The two most important risk factors for COPD were smoking (99\% of the physicians) and air pollution (37\%), followed by bacterial and/or viral infections (29\%) and genetic predisposition (26\%). Almost half of the respondents (49\%) reported that $16 \%-30 \%$ of their patients experienced an exacerbation per year requiring therapy with systemic steroids and/or antibiotics. Eighteen percent of the physicians stated that $31 \%-50 \%$ of their COPD patients had at least one moderate exacerbation per year. Hospitalizations due 
Table I Demographic characteristics of respondents $(n=590)$

\begin{tabular}{ll}
\hline & Proportion (n and \%) \\
\hline Age group & $46(7.8)$ \\
$30-40$ years & $240(40.7)$ \\
4 I-50 years & $225(38.1)$ \\
5 I-60 years & $70(11.9)$ \\
$>60$ years & $9(1.5)$ \\
Missing data & \\
Sex & $447(75.8)$ \\
Men & $132(22.4)$ \\
Women & $11(1.9)$ \\
Missing data & \\
Specialty & $565(95.8)$ \\
Pulmonologist & $15(2.5)$ \\
Internist & $10(1.7)$ \\
Missing data & \\
Location of practice & $285(48.3)$ \\
Urban & $289(49.0)$ \\
Rural & $17(2.9)$ \\
Missing data & \\
Practice type & $269(45.6)$ \\
Single practice & $214(36.3)$ \\
Single-speciality group practice & $95(16.1)$ \\
Multi-speciality group practice & $13(2.2)$ \\
Missing data & $152(25.8)$ \\
Length of time in practice & $123(20.8)$ \\
$<5$ years & $209(35.4)$ \\
$5-I 0$ years & $96(16.3)$ \\
II-20 years & $10(1.7)$ \\
$>20$ years & \\
Missing data & \\
\hline
\end{tabular}

to exacerbations were reported less frequently: $61 \%$ of the physicians stated that $<5 \%$ of their patients had at least one exacerbation-related hospitalization per year.

\section{Diagnosis of COPD}

Table 2 illustrates the respondents' criteria for diagnosis of COPD. Ninety-one percent of the physicians stated that a diagnosis of "suspected COPD" is reasonable in patients showing symptoms such as cough, expectoration, shortness of breath, and/or risk factors for COPD. The most relevant test for patients with suspected COPD was considered to be body plethysmography (66\% of pulmonary specialists), followed by spirometry $(32 \%)$.

As reported by the physicians, diagnosis of COPD is primarily based on a forced expiratory volume in 1 second/ (forced) vital capacity $\left(\mathrm{FEV}_{1} / \mathrm{VC}\right)$ index of $<70 \%$ (61\% of the physicians). On the other hand, $27 \%$ of the physicians used the WHO criteria for chronic bronchitis instead. Of the respondents, 85\% applied the correct spirometric criteria to assess the severity of moderate (GOLD II) COPD, with $87 \%$ and $77 \%$ of respondents using the criteria to assess the
Table 2 Criteria used by respondents to diagnose COPD

\begin{tabular}{|c|c|}
\hline & Proportion ( $\mathrm{n}$ and \%) \\
\hline \multicolumn{2}{|l|}{ Diagnostic criteria for COPD } \\
\hline $\mathrm{FEV}_{1} / \mathrm{VC}$ ratio of $<70 \%$ predicted & $358(60.7)$ \\
\hline Cough and sputum for & $157(26.6)$ \\
\hline \multicolumn{2}{|l|}{3 months in 2 consecutive years } \\
\hline $\mathrm{FEV}_{1}$ of $<80 \%$ predicted & $53(9.0)$ \\
\hline $\mathrm{FEV}_{1}$ of $<\mathrm{I} .5 \mathrm{~L}$ & $7(1.2)$ \\
\hline $\begin{array}{l}\text { Signs of pulmonary emphysema } \\
\text { on chest X-ray }\end{array}$ & $5(0.8)$ \\
\hline Hypoxemia and/or hypercapnia & $4(0.7)$ \\
\hline Missing data & $12(2.0)$ \\
\hline \multicolumn{2}{|l|}{ Definition of moderate COPD } \\
\hline $\begin{array}{l}\mathrm{FEV}_{1} / \mathrm{VC} \text { ratio of }<70 \%+\mathrm{FEV}, \\
\text { of }<80 \% \text { but } \geq 50 \% \text { predicted }\end{array}$ & $504(85.4)$ \\
\hline $\begin{array}{l}\mathrm{FEV}_{1} / \mathrm{VC} \text { ratio of }<70 \%+\mathrm{FEV}_{1} \\
\text { of }<50 \% \text { predicted }\end{array}$ & $63(10.7)$ \\
\hline $\begin{array}{l}\text { Clinical symptoms (dyspnoea, } \\
\text { reduced physical capacity) }\end{array}$ & $9(1.5)$ \\
\hline $\mathrm{FEV}_{\mathrm{l}} / \mathrm{VC}$ ratio of $<50 \%$ & $5(0.8)$ \\
\hline $\mathrm{FEV}_{1}$ of $>\mathrm{I} \mathrm{L}$ & I $(0.2)$ \\
\hline Missing data & $10(1.7)$ \\
\hline \multicolumn{2}{|l|}{ Definition of severe COPD } \\
\hline $\begin{array}{l}\mathrm{FEV}_{1} / \mathrm{VC} \text { ratio of }<70 \%+\mathrm{FEV}, \\
\text { of }<50 \% \text { but } \geq 30 \% \text { predicted }\end{array}$ & $514(87.1)$ \\
\hline $\mathrm{FEV}_{\mathrm{l}} / \mathrm{VC}$ ratio of $<50 \%$ & $51(8.6)$ \\
\hline $\begin{array}{l}\text { Clinical symptoms } \\
\text { (severe dyspnea at rest) }\end{array}$ & $15(2.5)$ \\
\hline 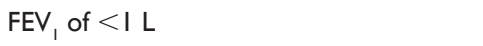 & $5(0.8)$ \\
\hline $\begin{array}{l}\mathrm{FEV}_{1} / \mathrm{VC} \text { ratio of }<70 \%+\mathrm{FEV}, \\
\text { of }<80 \% \text { predicted }\end{array}$ & $2(0.3)$ \\
\hline Missing data & $10(1.7)$ \\
\hline \multicolumn{2}{|l|}{ Definition of very severe COPD } \\
\hline $\begin{array}{l}\mathrm{FEV}_{1} / \mathrm{VC} \text { ratio of }<70 \%+\mathrm{FEV}_{1} \\
\text { of }<30 \% \text { predicted }\end{array}$ & $452(76.6)$ \\
\hline $\begin{array}{l}\mathrm{FEV}_{1} / \mathrm{VC} \text { ratio of }<70 \%+\mathrm{FEV}_{1} \\
\text { of }<50 \% \text { predicted }+ \text { chronic respiratory } \\
\text { failure (signs of right-sided heart failure) }\end{array}$ & $327(55.4)$ \\
\hline $\mathrm{FEV}_{1} / \mathrm{VC}$ ratio of $<30 \%$ & $70(11.9)$ \\
\hline $\begin{array}{l}\text { Clinical symptoms (severe dyspnea } \\
\text { at rest, frequent exacerbations) }\end{array}$ & $30(5.1)$ \\
\hline 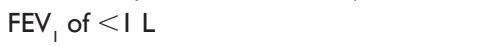 & $20(3.4)$ \\
\hline Missing data & II (I.9) \\
\hline
\end{tabular}

Note: Respondents $(n=590)$ could give more than one answer to all questions. Abbreviations: $\mathrm{FEV}_{1}$, forced expiratory volume in I second; VC, vital capacity.

severity of severe (GOLD III) and very severe (GOLD IV) COPD, respectively.

\section{Patient education}

Ninety-seven percent of the physicians stated that they or their staff regularly instructed patients in the correct use of inhalers. Most physicians advised their patients to stop smoking at every visit: (moderate COPD 78\%, severe/very severe COPD 83\%) or several times a year (moderate COPD 20\% severe/very severe COPD $14 \%$ ). A total of $60 \%$ of the respondents considered it difficult to implement measures to help patients give up smoking. 


\section{Treatment}

The two most important indicators of successful treatment as stated by pulmonary specialists were improved functional exercise capacity (72\%) and quality of life (52\%), followed by the prevention of exacerbations (Figure 1). The treatments prescribed by doctors for at least $50 \%$ of their patients with moderate to severe COPD based on the GOLD classification are summarized in Figure 2. Long-acting bronchodilators ( $\beta_{2}$-agonists and/or anticholinergics) were the most commonly prescribed treatments. Short-acting bronchodilators $\left(\beta_{2}\right.$-agonists or anticholinergics) and inhaled steroids, on the other hand, were rarely prescribed on their own. A combination of long-acting $\beta_{2}$-agonists and long-acting anticholinergics is primarily prescribed for severe COPD. The percentage of patients with moderate COPD treated with theophylline was low, but was markedly higher in severe COPD. Long-term treatment (>3 months) with inhaled steroids in combination with long-acting bronchodilators was used primarily for patients with severe to very severe COPD. A relatively low portion of patients with moderate and severe to very severe COPD were given a yearly influenza vaccination by pulmonary specialists (Figure 1).

The most important criteria for long-term therapy with inhaled glucocorticosteroids in addition to long-acting bronchodilators were COPD with $\mathrm{FEV}_{1}$ of $<50 \%$ and at least one exacerbation in the past year requiring treatment with systemic steroids and/or antibiotics ( $73 \%$ of the physicians) as well as improved symptoms due to inhaled glucocorticosteroids $(71 \%)$. Of the pulmonary specialists, $85 \%$ said they prescribed oral glucocorticosteroids for a short time only in the case of exacerbations. Of the physicians, $62 \%$ felt pulmonary rehabilitation was indicated in the case of moderate COPD (GOLD II), while $31 \%$ believed this was only necessary in severe forms of COPD (GOLD III 29\%, GOLD IV 2\%). In practice, only a small percentage of patients with moderate $(2 \%)$ or severe/very severe COPD $(16 \%)$ actually received pulmonary rehabilitation.

\section{Assessment of the benefits of therapeutic measures}

The results of an assessment of the benefits of various treatments are given in Table 3. Nicotine abstinence was seen as the most effective measure for prolonging life expectancy and slowing down the progression of the disease. The major advantages of pulmonary rehabilitation were seen in an improvement in exercise capacity, quality of life, and symptoms.

The assessment of the benefits of short-acting bronchodilators ( $\beta_{2}$-agonists, anticholinergics) was based primarily on the improvement in clinical symptoms, exercise capacity, and quality of life. Compared with the benefits attributed to long-acting bronchodilators ( $\beta_{2}$-agonists, anticholinergics) - including the positive impact on symptoms, exercise capacity, quality of life, and exacerbations - theophylline was felt to be of limited clinical benefit. Reductions in exacerbations were quoted in connection with long-acting bronchodilators, inhaled corticosteroids, and the combination of these drugs. Long-term oxygen therapy, when used, was seen as an effective measure for improving quality of life, exercise capacity, symptoms, and mortality. Contrary to the evidence from clinical trials and guideline recommendations, longacting bronchodilators, inhaled corticosteroids, and pulmonary rehabilitation were found to have some impact on disease progression and mortality.

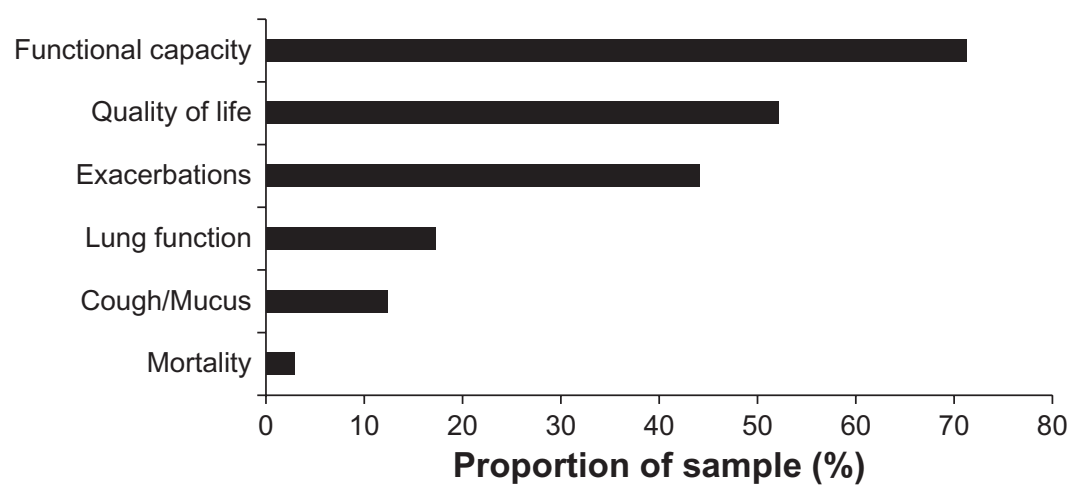

Figure I The most relevant treatment goals for COPD as seen by pulmonary specialists.

Notes: Improvements in functional (exercise) capacity (72\%) and quality of life (52\%) were rated highest by the physicians, followed by a reduction of COPD exacerbations ( $44 \%$ ). Effects on lung function (17\%), cough/sputum production (12\%) and, in particular, on mortality (3\%) were seen as less important indicators of success. Two answers were required for this question; $\mathrm{n}=590$. 


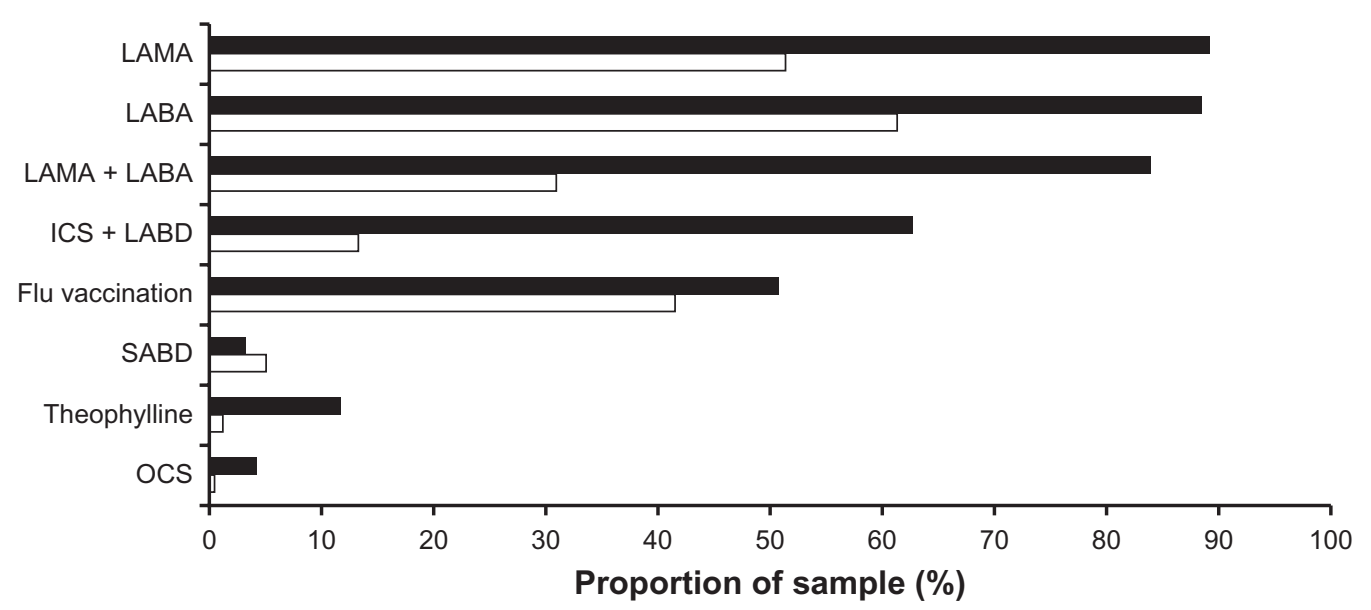

Figure 2 Treatment given by pulmonary specialists to $\geq 50 \%$ of their patients.

Notes: Moderate COPD (white columns) or severe to very severe COPD (black columns) according to the GOLD severity classification. ${ }^{5}$ Several answers were possible for this question; $\mathrm{n}=590$.

Abbreviations: LAMA, long-acting muscarinic agonist; LABA, long-acting beta-agonists; ICS, inhaled corticosteroids; LABD, long-acting bronchodilators (LABA and/or LAMA); SABD, short-acting bronchodilators (SABA and/or SAMA); OCS, oral corticosteroids.

\section{Knowledge and acceptance of current COPD guidelines}

Fifty-three percent of the participants regarded the recommendations contained in the national and international guidelines for the diagnosis and treatment of COPD as very useful while $46 \%$ found them suitable for guidance. The most relevant guideline on diagnosis and therapy of COPD was the current national COPD guidelines (51\%) followed by the international GOLD guidelines (40\%).

\section{Discussion}

Evidence-based guidelines aim to improve the medical care of patients and support physicians in making the appropriate diagnosis and initiating adequate measures for prevention and therapy. This local survey investigated the outpatient management of practicing pulmonary specialists in relation to current guideline recommendations for COPD.

The updated German COPD Guidelines ${ }^{7}$ now conform to the international GOLD guidelines ${ }^{5,6}$ regarding severity classification and treatment recommendations. In the present survey, this realignment has led to improvements in COPD severity classification and treatment compared with a previous survey based on the former national COPD Guidelines of $2002 .{ }^{17}$ However, it must be pointed out that the national COPD guidelines, like the American Thoracic Society/ European Respiratory Society (ATS/ERS) consensus on clinical pulmonary function testing, defines obstruction on the basis of the $\mathrm{FEV}_{1} / \mathrm{VC}$ ratio. ${ }^{7,18}$ In borderline cases, this could mean discrepancies compared with GOLD. Acceptance was high among the physicians questioned and in contrast

Table 3 Evaluation of the clinical benefits of various treatments

\begin{tabular}{|c|c|c|c|c|c|c|c|}
\hline & \multicolumn{7}{|c|}{ Proportion of respondents (\%) } \\
\hline & $\begin{array}{l}\text { Slows disease } \\
\text { progression }\end{array}$ & $\begin{array}{l}\text { Prolongs } \\
\text { life }\end{array}$ & $\begin{array}{l}\text { Improves physical } \\
\text { capacity }\end{array}$ & $\begin{array}{l}\text { Reduces } \\
\text { exacerbation rate }\end{array}$ & $\begin{array}{l}\text { Improves } \\
\text { symptoms }\end{array}$ & $\begin{array}{l}\text { Improves } \\
\text { quality of life }\end{array}$ & $\begin{array}{l}\text { No } \\
\text { benefits }\end{array}$ \\
\hline No smoking & 94.9 & 86.1 & 79.5 & 76.3 & 75.1 & 74.2 & 0 \\
\hline SABD & 2.4 & 3.7 & 68.8 & 9.2 & 91.7 & 48.5 & 1.4 \\
\hline LAMA & 45.6 & 27.8 & 91.0 & 79.7 & 87.6 & 88.8 & 0.2 \\
\hline LABA & 26.4 & 15.3 & 89.7 & 49.3 & 91.4 & 83.9 & 0.5 \\
\hline ICS & 21.5 & 9.7 & 27.5 & 88.6 & 61.2 & 49.5 & 3.1 \\
\hline ICS + LABA & 33.2 & 16.3 & 80.8 & 87.5 & 86.6 & 81.0 & 1.7 \\
\hline OCS & 6.3 & 6.9 & 39.2 & 24.9 & 77.5 & 40.8 & 10.8 \\
\hline PR & 28.6 & 32.4 & 92.5 & 45.8 & 75.6 & 89.5 & 1.7 \\
\hline LTOT & 4.2 & 77.1 & 78.8 & 8.5 & 71.2 & 84.9 & 0.2 \\
\hline Theophylline & 4.1 & 1.7 & 41.2 & 11.9 & 75.6 & 30.3 & 17.8 \\
\hline
\end{tabular}

Note: Respondents $(n=590)$ could give more than one answer for any of the interventions.

Abbreviations: ICS, inhaled corticosteroids; LABA, long-acting $\beta_{2}$-agonists; LAMA, long-acting muscarinic agonists; LTOT, long-term oxygen therapy given for I6-24 hours/day; OCS, oral corticosteroid; PR, pulmonary rehabilitation; SABD, short-acting bronchodilators. 
to a previous survey there was a preference for the national COPD guidelines. ${ }^{16}$ This may be a reflection of the fact that the GOLD guidelines are aimed at an international readership with a wide range of access to health care and treatment, while the recommendations of the national COPD guidelines are tailored to the specifics of the German health care system.

Pulmonary specialists were well aware of the epidemiological and health-economic dimensions of the disease. Questions about diagnosis criteria for COPD prompted different responses. More than half of the pulmonary specialists used the fixed $\mathrm{FEV}_{\mathrm{l}} /$ $\mathrm{VC}$ ratio as a criterion for diagnosing COPD. On the other hand, $26.6 \%$ of the participants considered the classical WHO criterion of chronic bronchitis (former GOLD class 0 ) as an indicator for diagnosis. However, this was an $11.6 \%$ decrease compared with a previous study in the same country. ${ }^{16}$

There were slight deficiencies in terms of grading COPD according to spirometric criteria. About $85 \%-87 \%$ of participants applied appropriate lung function criteria for the classification of moderate to severe COPD. There was greater disparity when describing very severe COPD - defined as either $\mathrm{FEV}_{1}<30 \%$ or $\mathrm{FEV}_{1}<50 \%$ predicted plus the presence of chronic respiratory failure - and this may indicate a particular degree of uncertainty with regard to the additional criteria of ventilatory failure or right heart insufficiency. Pulmonary specialists felt the most important aims of therapy were improvement in functional exercise capacity and quality of life, followed by prevention of exacerbations. This is well in line with the leading symptoms of patients with COPD, who primarily complain of shortness of breath upon exercise and the lasting impact of exacerbations. However, this survey did not explore how physicians' views might differ from patients' views. Interestingly, the positive impact on mortality was not of particular significance to physicians in terms of treatment objectives. This probably reflects the minor effect of symptomatic medical treatment and the - at best - modest effect of interventions, such as oxygen therapy, on mortality. Given the practical relevance of physical activity to address disease progression and the impact of pharmacotherapy in COPD, the development of valid and practicable instruments to measure physical activity is urgently required. ${ }^{19-21}$

Two-thirds of the respondents prescribed a combination of a long-acting $\beta_{2}$-agonist and an anticholinergic for more than half of their patients with severe COPD. Inhaled steroids and theophylline were also prescribed considerably more often in this patient group than for patients with moderate COPD. In line with the recommendations of current national and international guidelines, most pulmonary specialists prescribed systemic steroids for exacerbations only. ${ }^{5-7}$ The relatively low number of influenza vaccinations prescribed by pulmonary specialists contrasts with guideline recommendations. This might be explained by the fact that flu vaccinations are mainly performed by general practitioners in Germany.

Guidelines consider pulmonary rehabilitation to be standard care for those with at least moderate COPD (GOLD II) or at any stage in the presence of symptoms and disability. ${ }^{5-7}$ However, pulmonary rehabilitation was not prescribed as often as it should have been despite the known benefits, even in the advanced stages of the disease. There is now strong support for pulmonary rehabilitation in the event of COPD following recent hospitalization for an exacerbation. ${ }^{22-25}$ Pulmonary rehabilitation could thus already be organized during hospitalization for an exacerbation. However, there are issues surrounding specific aspects of pulmonary rehabilitation in the local health system - for instance, the motivation of physicians and patients, a significant administrative burden, financial incentives, or the limited availability of qualified and certified centers - that are likely to have prevented more widespread implementation of pulmonary rehabilitation in Germany so far.

In some cases, assessment of the clinical benefit of various pharmacological and non-pharmacological procedures, as offered by the office-based clinicians surveyed, conflicted with the clinical evidence from randomized clinical trials. For instance, so far no data are available from studies that corroborate the effect of pulmonary rehabilitation, bronchodilators, or inhaled steroids on mortality and the progression of the disease. ${ }^{5,6}$ We also found certain discrepancies between COPD guidelines and routine treatments. Some treatments such as inhaled corticosteroids (ICS) were overused in moderate COPD, whereas rehabilitation was not prescribed in a substantial number of cases in which it would have been indicated. Finally, a significant percentage of respondents still used the WHO definition of chronic bronchitis to define COPD.

As is the case with all self-reported surveys, the results of this study can be neither generalized nor confirmed. It is also unclear to what extent there was any positive selection bias, recall bias, or if respondents' answers differ from actual practice and knowledge or from those of non-pulmonary experts and non-participants. In addition, it remains unclear to what extent the treatment prescribed by physicians with a sound knowledge of the guidelines differs from that suggested by physicians who are less familiar with the current recommendations.

Overall, we found considerably greater conformity with guideline recommendations in terms of outpatient COPD management by pulmonary specialists compared to a previous survey in 2005. ${ }^{16}$ This suggests a high level of knowledge 
and significant progress in the implementation of COPD guidelines in Germany. However, even among pulmonary specialists there were certain deficits as regards the diagnosis and the pharmacological and non-pharmacological treatment of COPD. These gaps can be closed by using COPD guidelines for tailored education and training or as the foundation of national disease management programs for COPD. However, physicians' knowledge of the guidelines is not sufficient as the sole benchmark when assessing implementation of the guidelines in day-to-day practice. Necessary changes in the health care system must include more effective ways to transfer knowledge to clinical practice and to give access to interventions of proven clinical benefit.

\section{Acknowledgments}

The study was run and sponsored by Boehringer Ingelheim and Pfizer in cooperation with the Bundesverband der Pneumologen (BDP, Federal Association of Pneumologists). We thank Dr Heike Rau-Berger for her excellent technical assistance.

\section{Disclosure}

TG was an employee of Boehringer Ingelheim at the time of manuscript submission. CV received consulting fees and travel support from Boehringer Ingelheim; payment for board membership from AstraZeneca, Boehringer Ingelheim, GlaxoSmithKline, Mundipharma, Novartis, and Nycomed; fees for expert testimony and grant support from Talecris Biotherapeutics; and lecture fees from AstraZeneca, Boehringer Ingelheim, GlaxoSmithKline, Janssen, Merck, Novartis, Nycomed, and Talecris Biotherapeutics. AH declared no conflict of interest. $\mathrm{RB}$ has received reimbursement for attending scientific conferences, and/or fees for speaking and/or consulting from AstraZeneca, Boehringer Ingelheim, Chiesi, GlaxoSmithKline, Novartis, Nycomed, and Pfizer. The Pulmonary Department at Mainz University Hospital received financial compensation for services performed during participation in clinical trials organized by various pharmaceutical companies.

\section{References}

1. Lopez AD, Murray CC. The global burden of disease, 1990-2020. Nat Med. 1998;4(11):1241-1243.

2. Chapman KR, Mannino DM, Soriano JB, et al. Epidemiology and costs of chronic obstructive pulmonary disease. Eur Respir J. 2006;27(1):188-207.

3. Nowak D, Berger K, Lippert B, Kilgert K, Caeser M, Sandtmann R. Epidemiology and health economics of COPD across Europe: a critical analysis. Treat Respir Med. 2005;4(6):381-395.

4. Celli BR, MacNee W; ATS/ERS Task Force. Standards for the diagnosis and treatment of patients with COPD: a summary of the ATS/ERS position paper. Eur Respir J. 2004;23(6):932-946.
5. Global Initiative for Chronic Obstructive Lung Disease. Global strategy for the diagnosis, management, and prevention of COPD. 2009 update. Available from: http://www.goldcopd.org. Accessed August 25, 2010.

6. National Institute for Health and Clinical Excellence. Chronic obstructive pulmonary disease: Management of chronic obstructive pulmonary disease in adults in primary and secondary care. National Clinical Guideline Centre (2010). Available from: http://guidance.nice.org.uk/ CG101/Guidance/pdf/English. Accessed May 14, 2011.

7. Vogelmeier C, Buhl R, Criée CP, et al. Guidelines for the diagnosis and therapy of COPD issued by Deutsche Atemwegsliga and Deutsche Gesellschaft für Pneumologie und Beatmungsmedizin. Pneumologie. 2007;61(5):e1-e40. German.

8. Soler N, Ballester E, Martín A, Gobartt E, Miravitlles M, Torres A. Changes in management of chronic obstructive pulmonary disease (COPD) in primary care: EMMEPOC study. Respir Med. 2010;104(1):67-75.

9. Albers M, Schermer T, Molema J, et al. Do family physicians' records fit guideline diagnosed COPD? Fam Pract. 2009;26(2):81-87.

10. Löfdahl CG, Tilling B, Ekström T, Jörgensen L, Johansson G, Larsson K. COPD health care in Sweden - A study in primary and secondary care. Respir Med. 2010;104(3):404-411.

11. Bourbeau J, Sebaldt RJ, Day A, et al. Practice patterns in the management of chronic obstructive pulmonary disease in primary practice: the CAGE study. Can Respir J. 2008;15(1):13-19.

12. Rutschmann OT, Janssens JP, Vermeulen B, Sarasin FP. Knowledge of guidelines for the management of COPD: a survey of primary care physicians. Respir Med. 2004;98(10):932-937.

13. Lange P, Andersen KK, Munch E, et al. Quality of COPD care in hospital outpatient clinics in Denmark: The KOLIBRI study. Respir Med. 2009;103(11):1657-1662.

14. Harrold L, Field T, Gurwitz J. Knowledge, patterns of care, and outcomes of care for generalists and specialists. J Gen Intern Med. 1999;14(8):499-511.

15. Garcia-Aymerich J, Escarrabil J, Marrades RM, et al. Differences in COPD care among doctors who control the disease: general practitioner vs pneumologist. Respir Med. 2006;100(2):332-339.

16. Glaab T, Banik N, Rutschmann OT, Wencker M. National survey of guideline-compliant COPD management among pneumologists and primary care physicians. COPD. 2006;3(3):141-148.

17. Worth H, Buhl R, Cegla U, et al. Guidelines for the diagnosis and treatment chronic obstructive bronchitis and pulmonary emphysema issued by Deutsche Atemwegsliga and Deutsche Gesellschaft für Pneumologie. Pneumologie. 2002;56(11):704-738.

18. Pellegrino R, Viegi G, Brusasco V, et al. Interpretative strategies for lung function tests. Eur Respir J. 2005;26(5):948-968.

19. Watz H, Waschki C, Boehme M, et al. Extrapulmonary effects of chronic obstructive pulmonary disease on physical activity: a cross-sectional study. Am J Respir Crit Care Med. 2008;177(7):743-751.

20. Pitta F, Troosters T, Probst V, Langer D, Decramer M, Gosselink R. Are patients with COPD more active after pulmonary rehabilitation? Chest. 2008;134(2):273-280.

21. Glaab T, Vogelmeier C, Buhl R. Outcome measures in chronic obstructive pulmonary disease (COPD): strengths and limitations. Respir Res. 2010;11:79.

22. Riario-Sforza GG, Yacoub MR, Incorvaia C. Pulmonary rehabilitation as evaluated by clinical trials: an overview. Rev Recent Clin Trials. 2010;5(2):76-84.

23. Casaburi R, ZuWallack R. Pulmonary rehabilitation for management of chronic obstructive pulmonary disease. $N$ Engl J Med. 2009;360(13):1329-1335.

24. Seymour JM, Moore L, Jolley CJ, et al. Outpatient pulmonary rehabilitation following acute exacerbations of COPD. Thorax. 2010;65(5):423-428.

25. Puhan MA, Scharplatz M, Troosters T, Steurer J. Respiratory rehabilitation after acute exacerbation of COPD may reduce risk for readmission and mortality - a systematic review. Respir Res. 2005;6:54. 


\section{Publish your work in this journal}

The International Journal of COPD is an international, peer-reviewed journal of therapeutics and pharmacology focusing on concise rapid reporting of clinical studies and reviews in COPD. Special focus is given to the pathophysiological processes underlying the disease, intervention programs, patient focused education, and self management protocols.

This journal is indexed on PubMed Central, MedLine and CAS. The manuscript management system is completely online and includes a very quick and fair peer-review system, which is all easy to use. Visit http://www.dovepress.com/testimonials.php to read real quotes from published authors.

Submit your manuscript here: http://www.dovepress.com/international-journal-of-copd-journal 